\title{
TALKING GLOVE (HAND GESTURE RECOGNITION AND VOICE CONVERSION SYSTEM) USING THE SMARTPHONE
}

\author{
Bansal Harshit \\ Department of CSE \\ IMS Engineering College \\ Ghaziabad, Uttar Pradesh, India
}

\author{
Maurya Jyoti \\ Department of CSE \\ IMS Engineering College \\ Ghaziabad, Uttar Pradesh, India
}

\author{
Singh Abhishek \\ Department of CSE \\ IMS Engineering College \\ Ghaziabad, Uttar Pradesh, India
}

\begin{abstract}
Generally, a person who cannot communicate properly with others does not perceive linguistic communication. However, loudspeakers have a "deaf throat" in which they are self-aware and demoralized. According to the dumb, they have a meaning for every move. That message is set in the database. Equally, all the values/data are stored in the database. In real life, the example is delivered in the database of the microcontroller (ATmega32), and the motion sensor (Flex Sensors) in their hand is mounted. The motion sensors accelerate for every action and signal to the microcontroller (ATmega32). Sensor output could be a stream of information that varies from finger to bend. Flex sensors are among those sensors that amendment the resistance values based on the sensor's bend quantity. They convert the bend to electrical resistance, the greater the bend, the greater the resistance value. The output value from the sensor is digitally reborn and processed employing a microcontroller (ATmega32) and then responded to the voice. Use a smartphone speaker with a successful app. The system conjointly incorporates a Text to Speech Conversion (TTS) discourage that depicts organizing signals. This project tends to use Flex Sensors, microcontroller (ATmega32), and Smartphone Applications to get the output. Hardware elements embody microcontroller (ATmega32), Liquid Crystal Display (16x2), Flex sensor, HC-05 Bluetooth module, Regulator IC, power supply, and Smartphone with an application which can change over text to speech. Software tools used are Proteus, AVR Studio, and Android Studio. It is utilized in medical applications, wheelchair direction management, and artificial intelligence.
\end{abstract}

Keywords - Glove, Flex Sensor, HC-05 Bluetooth Module, Microcontroller (ATmega32)

\section{INTRODUCTION}

Correspondence between a visually impaired and hearing individual could be a significant weakness contrasted with correspondence between a visually impaired and past people. Language is additionally a nonverbal variety of intercourse found in deaf communities. So, our digital glove can recognize the sign made by our Hand in which we wear a glove and convert it into speech.

Ryan Patterson was the first person who designs first-hand speak glove. He began his mission together with his linguistic communication.

The main goal of this paper is to gift the matter of effectively translating gestures to the sounds of every text and sensitivity [3]. Glove-based full-fledged technology with a microcontroller (ATmega32) uses the Flex Glove interpreter.

For every hand gesture made, a feature is generated by the sensing element, compliments the hand's signal, and compares the management input to the controller gesture.

The training mode is sociable on the device. Therefore, it fits each user and will increase accuracy. The device will translate massive gestures that need one movement.

\section{WORKING OF THE SYSTEM}

At the initial stage, when our Hand is straight, i.e., when all the flex sensors in the glove are straight, then the flex sensors have the minimum value of resistance, and when we start bending our fingers at some angle, then resistance increases accordingly. Using these flex sensors, a potential divider circuit is made where the flex sensor is used as variable resistance, and another fixed value resistance is used in series with flex sensors.

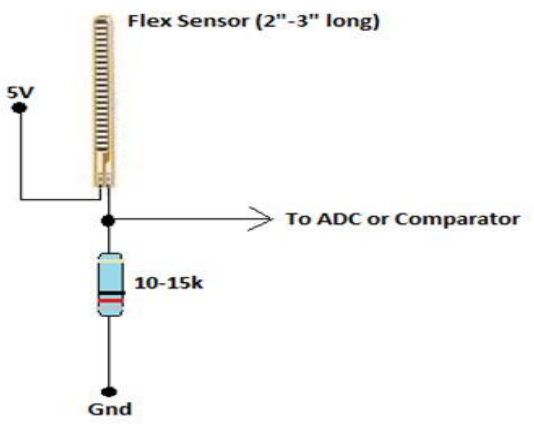

Fig. 1. Potential Divider Circuit 
On bending of fingers resistance of flex sensor changes accordingly so that voltage drop across flex sensor also changes. This potential drop across the flex sensor will be passed as an analog signal to the microcontroller (ATmega32) at port- $\mathrm{A}$, which then converted into a digital signal by the ADC feature of the microcontroller (ATmega32). Now, these digital values get computed using our algorithm, which is stored in microcontroller (ATmega32), and generates an output that will be an integer value. The basis of such considerations, the algorithm uses a different color image multiplied by the weighting coefficients of different ways to solve the visual distortion, and by embedding the watermark, wavelet coefficients of many ways, enhance the robustness of the watermark

This integer value generated by our algorithm will be passed via Bluetooth module $\mathrm{HC}-05$ to our mobile application, which is generated using Android Studio software in which we make use of some Java concepts named Collection.

In java, Collection is a Framework that has a class named HashMap, which works on key values pair (Key, Value). In our android application, we make use of this class (HashMap) in which the key is an integer value, and in place of value, we put the location of the audio file, which will be going to play.

Now, when the integer value reached to our application from Microcontroller (ATmega32), our android application will match the value of that integer with that of different values of "Key". When the match found, our application will look for the location of the audio file corresponding to that key value. When our application found the location of the audio file, it will get played via a mobile speaker or any other external speaker connected to that Smartphone.

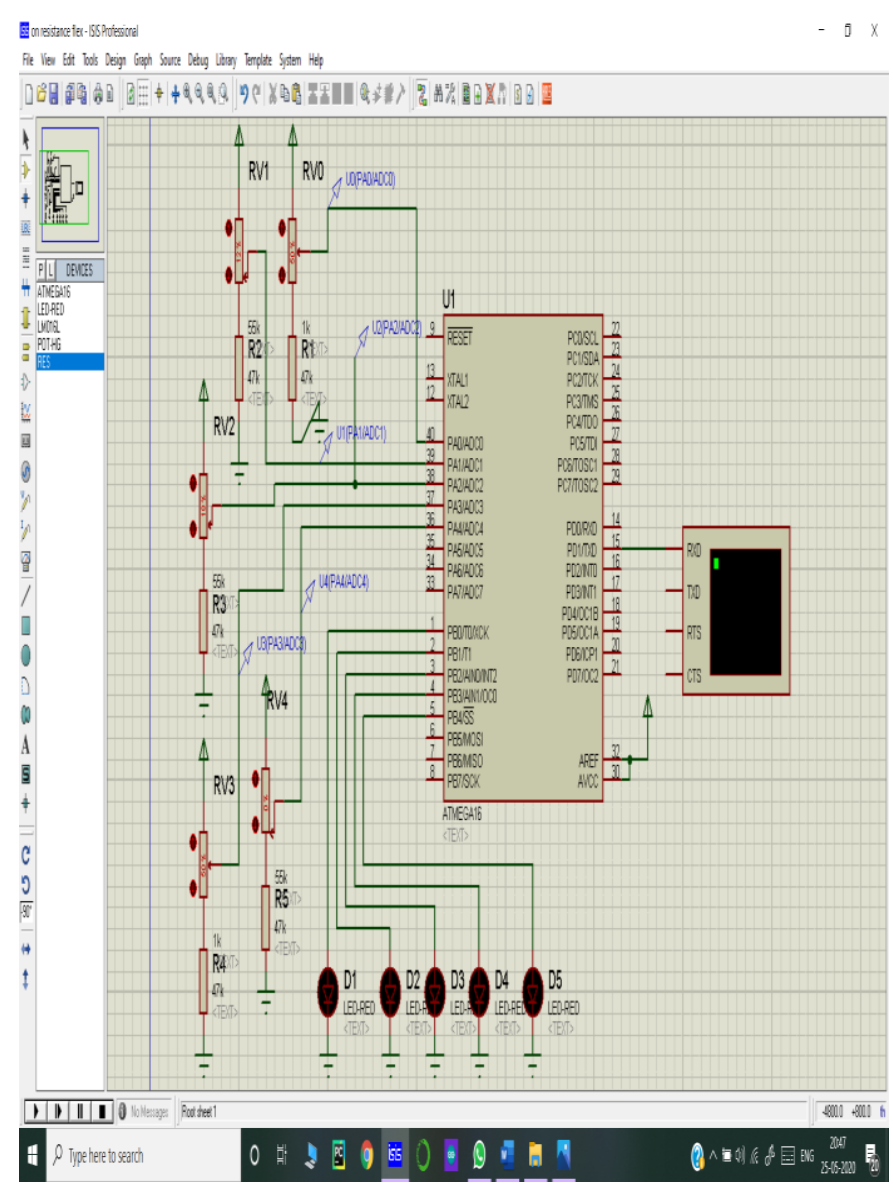

Fig. 2. Circuit Diagram of the System

\section{BLOCK DIAGRAM OF SYSTEM}

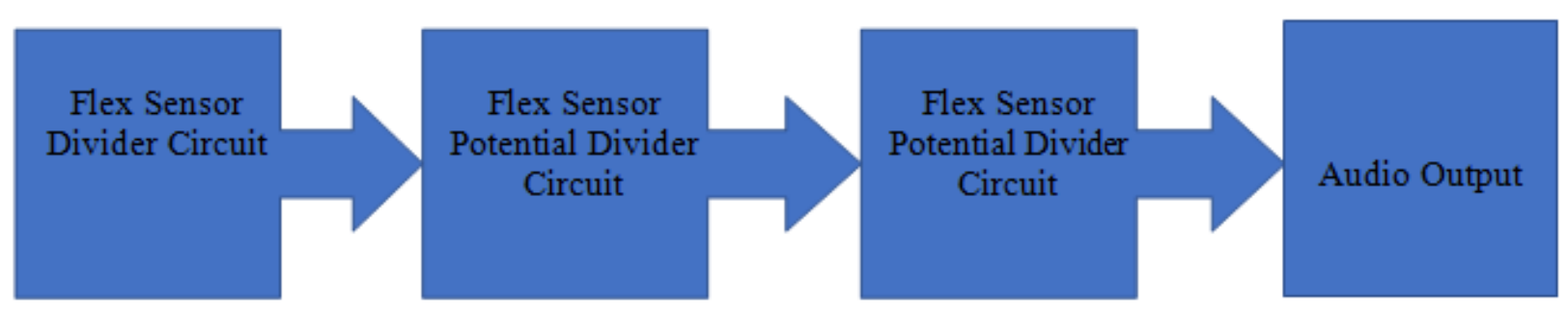




\section{International Journal of Engineering Applied Sciences and Technology, 2020 \\ Vol. 5, Issue 2, ISSN No. 2455-2143, Pages 269-273 \\ Published Online June 2020 in IJEAST (http://www.ijeast.com)}

Table -1 Values Stored In Smartphone As A Key Value Pair :

\begin{tabular}{|c|c|c|c|}
\hline \multirow{2}{*}{$\begin{array}{c}\text { Decimal } \\
\text { Number } \\
\text { (KEY) }\end{array}$} & \multicolumn{3}{|c|}{ Table Colunm Head } \\
\hline & $\begin{array}{l}\text { Binary } \\
\text { Number }\end{array}$ & $\begin{array}{c}\text { Sentence(In Hindi) } \\
\text { (Valne) }\end{array}$ & $\begin{array}{c}\text { Sentence } \\
\text { (In English) }\end{array}$ \\
\hline 01 & 00001 & $\begin{array}{c}\text { NAMASTE, AAP KAISE } \\
\text { HAI? }\end{array}$ & $\mathrm{Hi}$, how are you? \\
\hline 02 & 00010 & AAPKA SWAGAT HAI & Welcome. \\
\hline 03 & 00011 & $\begin{array}{l}\text { MERA NAME TALKING } \\
\text { HAND HAI }\end{array}$ & $\begin{array}{l}\text { My name is Talking } \\
\text { Hand. }\end{array}$ \\
\hline 04 & 00100 & $\begin{array}{l}\text { MAI BIMAR HU KRIPYA } \\
\text { DOCTOR KO BULAO }\end{array}$ & $\begin{array}{l}\text { I am sick, please } \\
\text { call the doctor. }\end{array}$ \\
\hline 05 & 00101 & MAI BHUKHA HU & I'm hungry. \\
\hline 06 & 00110 & MUJHE PANI DO & Give me water. \\
\hline 07 & 00111 & MUJHE COFFEE CHAHTYE & I need coffee. \\
\hline 08 & 01000 & $\begin{array}{c}\text { KYA AAP MERI } \\
\text { SAHAYTA KR SKTE HAI? }\end{array}$ & $\begin{array}{c}\text { Can you please help } \\
\text { me? }\end{array}$ \\
\hline 09 & 01001 & SHUPRABHAT & Good moming. \\
\hline 10 & 01010 & SHUBHRATRI & Good night. \\
\hline 11 & 01011 & AAPKA DIN KAISA RHA? & How was your day? \\
\hline 12 & 01100 & MUJHE DAWA CHAHTYE & I need medicine. \\
\hline 13 & 01101 & MUJHE THODA TIME DE & Give me some time. \\
\hline 14 & 01110 & APSE MIILE KHUSHI HUI & Glad to meet you. \\
\hline 15 & 01111 & MUJHE TOILET JANA HAI & $\begin{array}{l}\text { I need to go to } \\
\text { toilet. }\end{array}$ \\
\hline 16 & 10000 & MAI ABHI BUSY HU & I'm busy. \\
\hline 17 & 10001 & SHAMA KRE (PARDON) & I'm sonry. \\
\hline 18 & 10010 & ISE THIK SE KRE & Do it properly. \\
\hline 19 & 10011 & $\begin{array}{l}\text { AAP ACHHE LAG RHE } \\
\text { HAI }\end{array}$ & $\begin{array}{l}\text { You are looking } \\
\text { good. }\end{array}$ \\
\hline 20 & 10100 & $\begin{array}{l}\text { AAPNE ACHHA KAM } \\
\text { KIYA HAI }\end{array}$ & You did a nice job. \\
\hline 21 & 10101 & AAP KB AA RHE HAI? & $\begin{array}{l}\text { When are you } \\
\text { coming? }\end{array}$ \\
\hline 22 & 10110 & AAP KHA REHTE HAI? & Where do you live? \\
\hline 23 & 10111 & $\begin{array}{l}\text { MAI BAHAR JANA } \\
\text { CHAHTA HU }\end{array}$ & I want to go out. \\
\hline 24 & 11000 & AAP KYA KRTE HAI? & What do you do? \\
\hline 25 & 11001 & TIME KYA HUA HAI? & What is the time? \\
\hline 26 & 11010 & $\begin{array}{c}\text { VHA KHATRA HAI VHA } \\
\text { MT JAO }\end{array}$ & $\begin{array}{l}\text { There is danger, } \\
\text { don't go there. }\end{array}$ \\
\hline 27 & 11011 & $\begin{array}{c}\text { MUJHE APNE BARE ME } \\
\text { BTAO }\end{array}$ & $\begin{array}{l}\text { Tell me about } \\
\text { yourself. }\end{array}$ \\
\hline 28 & 11100 & $\begin{array}{l}\text { KYA AAP MUJHE VEH } \\
\text { VASTU DE SKTE HAI? }\end{array}$ & $\begin{array}{l}\text { Can you pass that } \\
\text { item? }\end{array}$ \\
\hline 29 & 11101 & APNA KHYAL RKHE & $\begin{array}{l}\text { Take care of } \\
\text { yourself. }\end{array}$ \\
\hline 30 & 11110 & MUJHE NHI PTA & I don't know. \\
\hline 31 & 11111 & APSE MIILR ACHHA LGA & Nice to meet you. \\
\hline
\end{tabular}

IV. HARDWARE DETAILS

A. Flex sensors

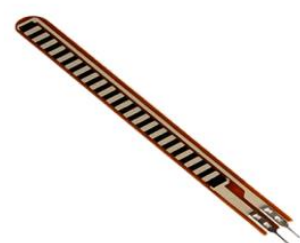

Flex sensors that are mounted on the glove are used to measure the amount of bending made by our Hand while wearing the glove consisting of the flex sensors. Usually, flex sensors are used to measure the resistance incurred at a different angles of the flex sensors.

B. ATmega32 (Microcontroller)

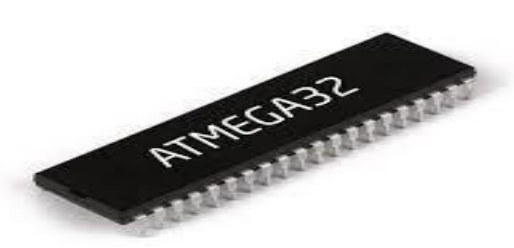

ATmega32 is an 8-bit AVR microcontroller that takes input from flex sensors and then computes the output by using the algorithm which is stored inside the microcontroller.

\section{PCB}

PCB (Printed Circuit Board) is used to electrically connect the electric appliances. In our hardware also, our whole circuit connected via PCB.

\section{D. $7805 \mathrm{IC}$}

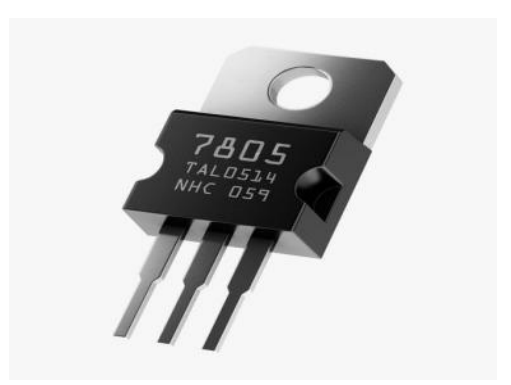

7805 IC is used to maintain the voltage at a constant value. It resists the voltage fluctuations in our circuit so that we get accurate value and our equipments work properly 


\section{International Journal of Engineering Applied Sciences and Technology, 2020 \\ Vol. 5, Issue 2, ISSN No. 2455-2143, Pages 269-273 \\ Published Online June 2020 in IJEAST (http://www.ijeast.com)}

without any damage which might occur due to voltage fluctuation in the absence of the 7805 IC.

\section{E. HC-05 Bluetooth Module}

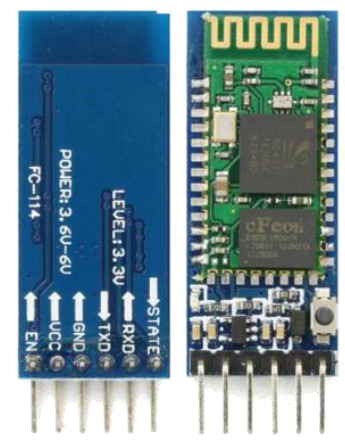

HC-05 is an SPP (Serial Port Protocol) Bluetooth module. In our project is used to transfer value from the microcontroller (ATmega32) to our Smartphone.

\section{SOFTWARE DETAILS}

\section{A. ATMEL Studio}

ATMEL Studio is a refined free advancement condition. It gives everything expected to consistently alter, fabricate, download, and troubleshoot applications on ATMEL microcontrollers. ATMEL Studio likewise oversees and gives an immediate interface to the ATMEL Programming System, and can legitimately get to the ATMEL Exhibition.

\section{B. Proteus}

The Proteus Design Suite is a restrictive programming device suite utilized basically for electronic plan computerization. Electronic structure specialists and professionals use the most part of the product to make schematics and electronic prints for assembling printed circuit sheets PCB

C. Android Studio

Android Studio is the authority coordinated advancement condition (IDE) for Android application improvement. It relies upon the IntelliJ IDEA, a Java composed headway condition for programming and merges its code changing and architect instruments.

To help application advancement inside the Android working framework, Android Studio utilizes a Gradle based form framework, emulator, code formats, and Github reconciliation. Each undertaking in Android Studio has at least one modality with source codes and asset documents.

\section{ALGORITHM}

Step 1: Start

Step 2: Input from all 5 flex sensors are transferred to the microcontroller as analog signal.

Step 3: That analog value gets converted to a digital signal.

Step 4: Then, those digital signal's value will get passed to ifelse conditions.

Step 5: In the if-else condition, the input signal range will be matched with one of the conditions.

Step 6: After satisfying the condition from one of the if-else conditions, the value assigned in that particular condition will get passed to the Smartphone via Bluetooth.

Step 7: After getting the decimal value in the Smartphone application, then that value gets passed to the if-else condition.

Step 8: In the application, that value will match using HASHMAP, which works on key-value pairs, now the value obtained via Bluetooth will match one of the values from 31 keys.

Step 9: When that value gets matched with one of the keys, then that key has some 'Value' which contains the path of the particular audio file associated with that key.

Step 10: After getting the path of the particular audio file, the audio gets played via Smartphone speaker or some external speaker connected to that smartphone.

\section{CONCLUSION}

Sign language is a useful sign to facilitate communication between the deaf or mute community. The goal of this project is to reduce the communication gap between a quiet society and, in addition, the standard world. In global applications, this system helps the deaf and dumb who cannot communicate with the other person. The best part of this project is assigning a complete sentence rather than words or characters with respect to each particular gesture made by the person wearing that glove. The biggest feature of this project is that the Gesture symbol may be an associate autonomous system that applies to common living spaces. It is weak, and para-lis is useful to the patient, which means they are not speaking properly and are also used for intelligent home applications and industrial applications. 


\section{International Journal of Engineering Applied Sciences and Technology, 2020 \\ Vol. 5, Issue 2, ISSN No. 2455-2143, Pages 269-273 \\ Published Online June 2020 in IJEAST (http://www.ijeast.com)}

\section{REFERENCE}

[1] Nitipon Navaitthiporn, Preeyarat Rithcharung, Phitnaree Hattapath, C. Pintavirooj, "Intelligent glove for sign language communication", 2019 12th Biomedical International Conference (BMEiCON).

[2] Shahrukh Javed, Ghousia Banu, J Aarthy Suganthi Kani, Ateequeur Rahman, "Wireless Glove for Hand Gesture Acknowledgement: Sign Language to Discourse Change Framework in Territorial Dialect", Robotics \& Automation Engineering Journal, Volume 3, Issue 2, June 2018.

[3] Sruthi Dinesh, "Talking Glove- A Boon for the Deaf, Dumb and Physically Challenged", International Journal of Advanced Research in Electronics and Communication Engineering (IJARECE) Volume 4, Issue 5, May 2015.

[4] Prof. Raviprakash Shriwas, Mr. Nitesh Vihirkar, Ms. Kshama Morey, Ms. Nikhita Gulhane, "A Preview Paper on Hand Talk Glove", International Journal for Research in Applied Science \& Engineering Technology (IJRASET) Volume 3, Issue 4, April 2015.

[5] Thilagavathy, Jeyapaul Murugan, S. Darwin, "Embedded Based Hand Talk Assisting System for Deaf and Dumb", International Journal of Engineering Research \& Technology (IJERT) Volume 3, Issue 3, March 2014.

[6] Anusha L, Usha Devi Y (2016) Implementation Of Gesture Based Voice And Language Translator For Dumb People. International Conference on Communication and Electronic Systems (ICCES) ISBN:978-1-5090- 1066-0.

[7] Abhijith Bhaskaran K, Anoop G Nair (2016) Smart Gloves for Hand Gesture Recognition Sign Language to Speech Conversion System. Department of ECE, 2016 International Conference on RAHA ISBN: 978-1-50905203-5.

[8] Ansari AH, Ashwini Sanjay (2016) Giving Voice To Mute People Using Flex Sensor. 2016 IJARIIE-ISSN(O)2395-4396 2(3).

[9] Kalpattu S, Abhishek, Derek Ho (2016) Glove Base And Gesture Recognition Sign Language Translator Using Capacitive Touch Sensor. IEEE International Conference on Electron Devices and Solid-State Circuits. ISBN: 9781-5090-1830-7.

[10] Jadhav BD, Nipun Munot, Madhura Hambarde, Jueli Ashtikar (2015) IJCSN International Journal of Computer Science and Network ISSN (Online) : 2277-5420 6. Aarthi M, Vijayalakshmi P (2016) Sign Language to Speech Conversion. Department of ECE Department of ECE, SSN College of Engineering SSN College of Engineering.

[11] Celestine Preetham, Girish Ramakrishnan, Sujan Kumar, Anish Tamse, Nagendra Krishnapura, (2013) Hand TalkImplementation of a Gesture Recognizing Glove.
Department of Electrical Engineering, Indian Institute of Technology Madras, Bangalore, India.

[12] Pooja Gupta, Dr. Ambuj Kumar Agrawal, Shahnaz Fatima (2014) Sign Language Problem And Solutions For Deaf And Dumb People. pp. 124- 127.

[13] Sawant Pramada, Deshpande Saylee, Nale Pranita, Nerkar Samiksha, Archana S Vaidya (2013) Intelligent Sign Language Recognition Using Image Processing 3(2): $45-$ 50.

[14] Kunal A Wankhade, Gauri N Zade (2014) Sign Language Recognition For Deaf And Dumb People Using ANFIS 3(5): 1206-1209. 11. Kiratey Patil, Gayatri Pendharkar, Gaikwad GN (2014) American Sign Language Detection 4(11): 1-5.

[15] Shanmukha Swamy MN, Chethan MP, Mahantesh Gatwadi (2014) Indian Sign Language Interpreter with Android Implementation 97(13): 36-40.

[16] Etsuko Ueda, Yoshio Matsumoto, Masakazu Imai, Tsulasa Ogasawara (2001) Hand Pose Estimation for Vision based Human Interface. In Proc 10th IEEE International Workshop on Robot and Human Communication (Roman 2001), pp. 473- 478.

[17] Claudia Nölker, Helge Ritter (1999) Visual Recognition of Hand Postures. In Proc International Gesture Workshop on Gesture-Based Communication in Human Computer Interaction, pp. 61-72. 0057 How to cite this article: Shahrukh J, Ghousia B S, J Aarthy S K, Ateequeur R. Wireless Glove for Hand Gesture Acknowledgment: Sign Language to Discourse Change Framework in Territorial Dialect. Robot Autom Eng J. 2018; $3(2)$ : 555609. 10.19080/RAEJ.2018.03.555609. Robotics \& Automation Engineering Journal

[18] Wilson AD, Bobick AF (2011) Learning visual behavior for gesture analysis. In Proc IEEE Symposium on Computer Vision.

[19] Zhang Qiu-yu, Lu Jun-chi, Zhang Mo-Yi, Duan Hong Xiang And Lv Lu (2015) Hand Gesture Segmentation Method Based on YCb Cr Color Space and K- Means Clustering. International Journal Of signal Processing, Image Processing and Pattern Recognition 8(5): 105- 116.

[20] Jorge Alberto Marcial Basilio, Gulaberto Aguilar Torres, Gabriel Sanchez Perez, Karina Toscano Medina L, Hector M Perez Meana (2011) Explicit Image Detection Using $\mathrm{YCbCr}$ Space Color Model as Skin Detection. Application of Mathematics and Computer Engineering, pp: $123-125$. 